\title{
Thermal Protection Systems Technology Transfer from Apollo and Space Shuttle to the Orion Program
}

\author{
Michael Stewart ${ }^{1}$ \\ Lockheed Martin, Kennedy Space Center, Florida, 32899 \\ and \\ William J. Koenig ${ }^{2}$ \\ NASA Kennedy Space Center, Florida, 32899 \\ and \\ Richard F. Harris ${ }^{3}$ \\ NASA Kennedy Space Center, Florida, 32899
}

This paper describes how the Orion program is utilizing the Thermal Protection System (TPS) experience from the Apollo and Space Shuttle programs to reduce program risk and improve affordability to meet NASA's future manned exploration missions. The Orion program successfully completed the Exploration Flight Test (EFT-1) mission in 2014 and is currently assembling, integrating, and testing the next spacecraft for the Exploration Mission (EM-1) to meet the flight test objectives of an unmanned orbital mission to the moon and return to earth in 2019. The Orion spacecraft production operations are located in the Neil Armstrong Operations and Checkout (O\&C) facility at the Kennedy Space Center (KSC) providing an affordable and seamless delivery approach of vehicles directly to the launch site eliminating spacecraft transportation and additional checkout testing. Innovative vehicle design, manufacturing and test operations approaches are maturing and evolving with each Orion vehicle build to support the challenging NASA exploration mission requirements beyond Low Earth Orbit (LEO) while reducing program cost and schedule impacts. An example of Orion's evolution is the incorporation of an improved heat shield design, assembly and testing approach to meet the higher re-entry velocities for a lunar return for the EM-1 mission. The EFT1 heat shield was based on the Apollo heat shield manufacturing processes and was assembled at a supplier location and then transported to KSC for final integration. The EM-1 heat shield is now manufactured, assembled, tested, and installed into the spacecraft at the $O \& C$ facility reducing program cost and production schedules. The transition of the Space Shuttle TPS capabilities has enabled Orion to provide a human rated capsule design using proven materials and processes established over years of orbiter re-entry missions. The Orion Crew Module (CM) TPS configuration is derived from the Apollo CM approach utilizing improved materials and processes developed from the Space Shuttle program. The Orion EFT-1 heat shield utilized the Avcoat ablative material from Apollo which was injected into a honeycomb substrate and has been updated for EM-1 incorporating a block configuration bonded to a composite shell structure. This approach utilizes the proven Avcoat material for the heat shield ablator and is utilizing derived bonding and inspection methods and techniques from the Space Shuttle tile experience. The Orion back shell TPS configuration is based on Space Shuttle tile designs using proven tile materials and coatings. The Orion forward bay cover utilizes the high temperature tiles similar to the back shell tiles and low temperature blankets derived from the Space Shuttle program reducing weight impacts. Space Shuttle Multi-Layer Insulation (MLI) is installed in the Orion capsule to control the interior temperature environment providing a light weight design. These TPS design approaches have performed successfully on the Orion first flight test on EFT-1 and are incorporated in the configuration for the next flight test for EM-1. Completion of these two flight tests will certify the TPS for the Orion program for human rated exploration missions and has reduced the development cost to the Orion program. In addition to transitioning the Space Shuttle TPS design configurations to Orion, the supporting manufacturing infrastructure, manufacturing processes, and

\footnotetext{
${ }^{1}$ Manufacturing Engineer Lead, Lockheed Martin Orion Program, KSC/O\&C ORION.

${ }^{2}$ Facilities Manager, NASA Orion Production Operations, KSC/O\&C ORION.

${ }^{3}$ Consultant, NASA Orion Production Operations, KSC/O\&C ORION, AIAA Member 763115.
}

1

American Institute of Aeronautics and Astronautics 
inspection methods are also incorporated into the Orion assembly operations at KSC. This has avoided significant startup schedule and costs impacts of new capabilities and development of support operations necessary to fabricate, install, inspect, and validate the TPS installations for the Orion spacecraft. The Thermal Protection System Facility (TPSF) which supported the Space Shuttle program provides the heat shield Avcoat blocks and the back shell AETB-8 tiles for Orion program. Extending the existing Space Shuttle TPS operations at KSC provides onsite support to the Orion spacecraft assembly operations. A significant benefit to the Orion program is the transition of the Space Shuttle technician work force at KSC. This highly skilled workforce was able to transition to the Orion program and immediately support the TPS installation operations. They brought with them the human rated manufacturing and assembly operations culture that was critical to the Space Shuttle success avoiding the retraining cost and schedule impacts of a new workforce to Orion. The technician skills certification program from the Space Shuttle was found to be compatible with the Lockheed Martin technician certification programs enabling a seamless training process utilizing process similarity avoiding the cost of retraining the work force to Orion standards. The existing workforce is certificated for multiple processes enabling reassignment of technicians to other tasks in the Orion AI\&P operations reducing the overall touch labor manpower requirements. Additional benefits of using the Space Shuttle workforce is the incorporation of the lessons learned from Space Shuttle processes to improve the Orion TPS processes. This has resulted in a continuous evolution of TPS processes to improve the producibility and reduce the program cost for the TPS for the Orion program. Transitioning the Apollo and Space Shuttle TPS designs, processes, and technician workforce has been instrumental in enabling Orion to successfully meet the program challenges for NASA's exploration missions of the future.

\section{Nomenclature}

$\begin{array}{ll}\text { AETB-8 } & =\text { Alumina Enhanced Thermal Barrier } \\ A F R S I & =\text { Advanced Flexible Reusable Surface Insulation } \\ A I \& P & =\text { Assembly, Integration \& Production } \\ A T V & =\text { Automated Transfer Vehicle } \\ C M & =\text { Crew Module } \\ C M A & =\text { Crew Module Adapter } \\ E C L S S & =\text { Environmental Control and Life Support System } \\ E F T-1 & =\text { Exploration Flight Test -1 } \\ E M-1 & =\text { Exploration Mission }-1 \\ E M-2 & =\text { Exploration Mission -2 } \\ E S A & =\text { European Space Agency } \\ E S M & =\text { European Service Module } \\ F R S I & =\text { Flexible Reusable Surface Insulation } \\ G N \& C & =\text { Guidance, Navigation \& Control } \\ H R S I & =\text { High Temperature Reusable Surface Insulation } \\ H S F & =\text { Human Space Flight } \\ I C P S & =\text { Interim Cryogenic Propulsion Stage } \\ I S S & =\text { International Space Station } \\ K S C & =\text { Kennedy Space Center } \\ L A S & =\text { Launch Abort System } \\ L E O & =\text { Low Earth Orbit } \\ L R S I & =\text { Low Temperature Reusable Surface Insulation } \\ M L I & =\text { Multi-Layer Insulation } \\ M M & =\text { Micrometeoroid } \\ M M O D & =\text { Micrometeoroid On-orbit Debris }\end{array}$




$\begin{array}{ll}N A S A & =\text { National Aeronautics and Space Association } \\ N D E & =\text { Non-Destructive Evaluation } \\ O \& C & =\text { Operations \& Checkout } \\ O D & =\text { On-orbit Debris } \\ P O D & =\text { Probability of Detection } \\ R C C & =\text { Reinforced Carbon-Carbon } \\ R O I & =\text { Region of Interest } \\ S A J & =\text { Spacecraft Adapter Jettisoned Fairings } \\ S L S & =\text { Space Launch System } \\ S M & =\text { Service Module } \\ S P C & =\text { Statistical Process Control } \\ T i & =\text { Titanium } \\ T P S & =\text { Thermal Protection System } \\ T P S F & =\text { Thermal Protection System Facility }\end{array}$

\section{Introduction}

$\mathrm{T}$ HE Orion program successfully completed the first Exploration Flight Test (EFT-1) in 2014 and is currently assembling, integrating, and testing the next Exploration Mission (EM-1) spacecraft to meet the objectives of an unmanned orbital mission to the moon and return to earth in 2019. The Orion program is implementing innovative vehicle design, manufacturing, and test operations approaches with each vehicle build to support the challenging exploration mission requirements beyond Low Earth Orbit (LEO). The Orion program is utilizing the Thermal Protection System (TPS) experience from the Apollo and Space Shuttle programs to reduce program risk and provide an affordable approach to meet NASA's challenging manned exploration missions. An example of Orion's innovation is the incorporation of an improved heat shield design, assembly and testing approach to meet the reentry velocities for a lunar return for the EM-1 mission. The EFT-1 heat shield was based on the Apollo heat shield manufacturing processes to meet an early flight test milestone which was assembled at a supplier location and transported to KSC for final integration. The EM-1 heat shield is an updated design and is now manufactured, assembled, tested, and installed into the spacecraft in a seamless operation located at KSC reducing program cost and production schedule. Orion program is further enhanced by transferring the Space Shuttle TPS experience for reentry protection systems to the Orion TPS hardware which utilizes re-entry tiles, thermal barriers, and Multi-Layer Insulation (MLI) configurations. The transition of the Space Shuttle TPS capabilities has enabled Orion to provide a human rated capsule design using proven manufacturing and assembly operations. This approach has avoided significant startup schedule and costs impacts of new capabilities and development of support operations necessary to fabricate, install, inspect, and validate the TPS installations for the Orion spacecraft. This transition strategy has also utilized the highly skilled Space Shuttle technician workforce and the existing TPS facilities at KSC to further benefit the Orion program.

The EM-1 flight test program overview shown in Figure 1 describes the second Orion flight test which is an unmanned mission to the moon and return to earth. The mission's primary objectives include the verification of the Orion software, the Guidance Navigation and Control (GN\&C) subsystem, the TPS heat shield and the recovery operations. The EM-1 flight test will be the first flight on NASA's new Space Launch System (SLS) launch vehicle which will take the spacecraft to lunar transfer orbit. This mission will utilize a Block 1 SLS configuration with an Interim Cryogenic Propulsion Stage (ICPS) which will allow Orion to fly a mission profile similar to future exploration missions. Although EM-1 will be an unmanned mission, it will support the certification of Orion for manned missions demonstrating critical mission functionality including the TPS systems for a re-entry for a lunar return. The EM-2 flight will be the first crewed mission and is planned in the early 2020s. The EM-1 TPS will experience an increased heat load for a lunar return at a velocity of approximately 7 miles per second which is about $20 \%$ greater than the EFT-1 re-entry velocity. The EM-1 heat shield is an updated design from the EFT-1 mission utilizing an improved structural configuration and an improved bonded ablation design. The back shell and forward bay cover utilizes existing Space Shuttle tile design which was used for the EFT-1 test flight. 


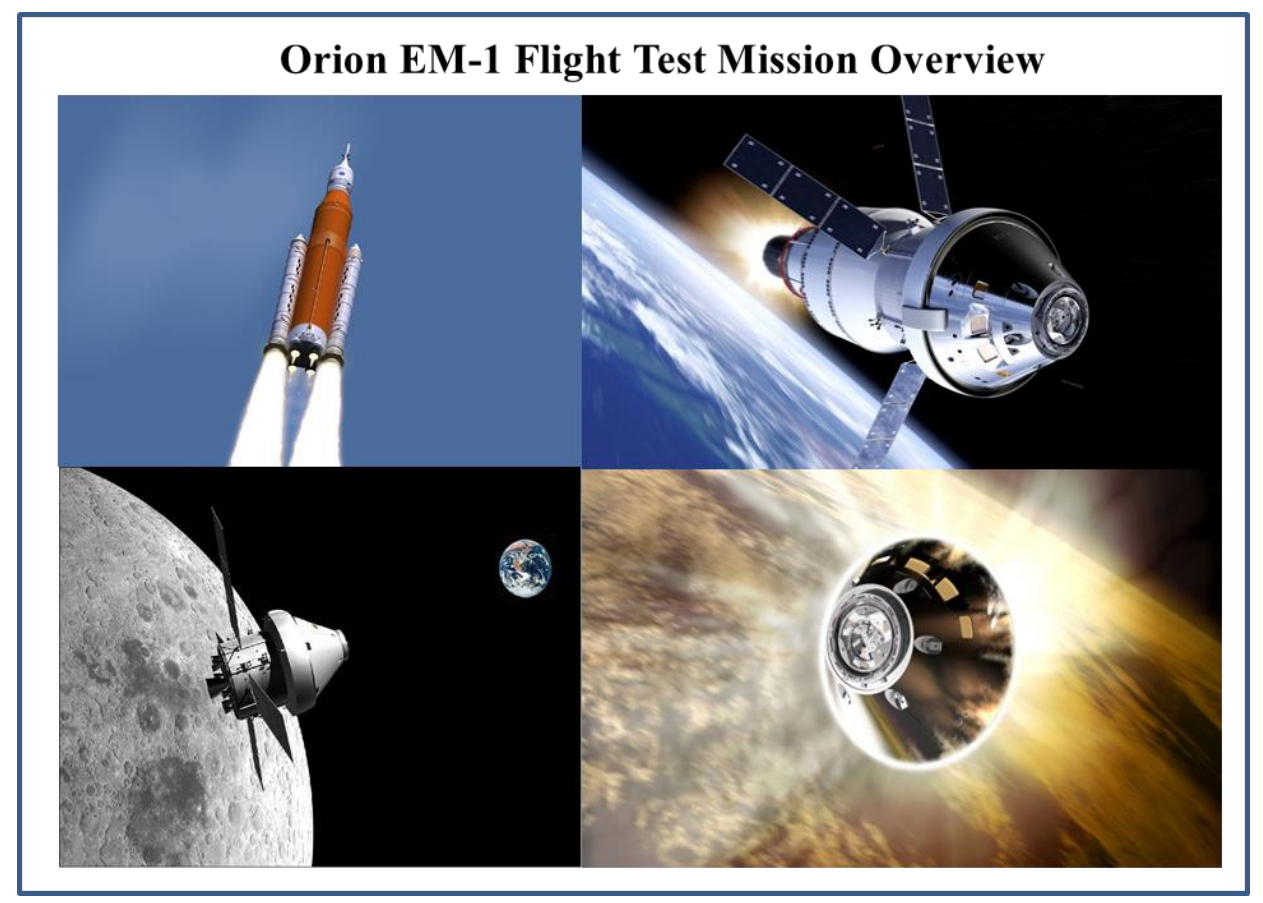

Figure 1. Overview of the Orion EM-1 flight test mission including launch on the NASA SLS, lunar transfer and return mission operations, and earth re-entry.

The Orion EM-1 configuration is shown in Figure 2 and will be launched on the SLS Block 1 launch vehicle. The elements of the Orion spacecraft include the Launch Abort System (LAS), Crew Module (CM), Crew Module Adapter (CMA), the European Service Module (ESM), and the Spacecraft Adapter Jettisoned Fairings (SAJ). The LAS enhances crew safety by enabling an abort jettison of the CM throughout all phases of the ascent profile from the launch pad through high altitude ascent. The CMA is integrated to the ESM providing propulsion, solar arrays, and support fluids during the on-orbit mission phases. The SAJ Fairings are jettisoned during the ascent phase to reduce on-orbit vehicle weight. The CM includes the heat shield, back shell panels and the forward bay cover which is jettisoned during return to enable parachute deployment. The EM-1 spacecraft will be unmanned and have limited Environmental Crew Life Support System (ECLSS) equipment to support the flight test mission requirements.

The LAS will perform a nominal separation from the EM-1 spacecraft during the ascent phase and will fly an inert abort motor configuration. An earlier risk reduction test has been completed for the LAS for an on pad abort test firing demonstrating the abort motor firing, attitude control and separation from the CM at low altitudes. An ascent abort test flight is planned to demonstrate the high altitude abort capability at supersonic aerodynamic conditions which will complete the risk reduction program for the LAS. The LAS provides a protective cover over the CM which protects the CM exterior from debris and ascent environments further improving crew safety during the ascent phase of the mission. The CMA and the ESM elements are integrated to provide the Service Module (SM) for the Orion spacecraft. An affordability initiative was implemented reducing Orion program development cost and schedule by utilizing the European Space Agency (ESA) spacecraft experience using the Automated Transfer Vehicle (ATV) design and has been adapted to perform the propulsion capabilities for the Orion service module. The CMA integrates to the ESM and provides the interface to the CM. Solar arrays providing electrical power are deployed from the ESM.

The TPS configurations used on the EM-1 vehicle provide ascent, orbital and re-entry protection during the mission phases. The CM utilizes TPS tiles on the forward bay cover and back shells and utilizes the TPS ablation blocks on the heat shield. The TPS additionally protects the CM for Micrometeoroid and On-orbit Debris (MMOD) impacts during on-orbit mission phases near earth orbit. The Orion TPS designs and material configurations and manufacturing processes utilize the flight proven TPS experience from Apollo and Space Shuttle programs enabling reduced program cost and schedule. 


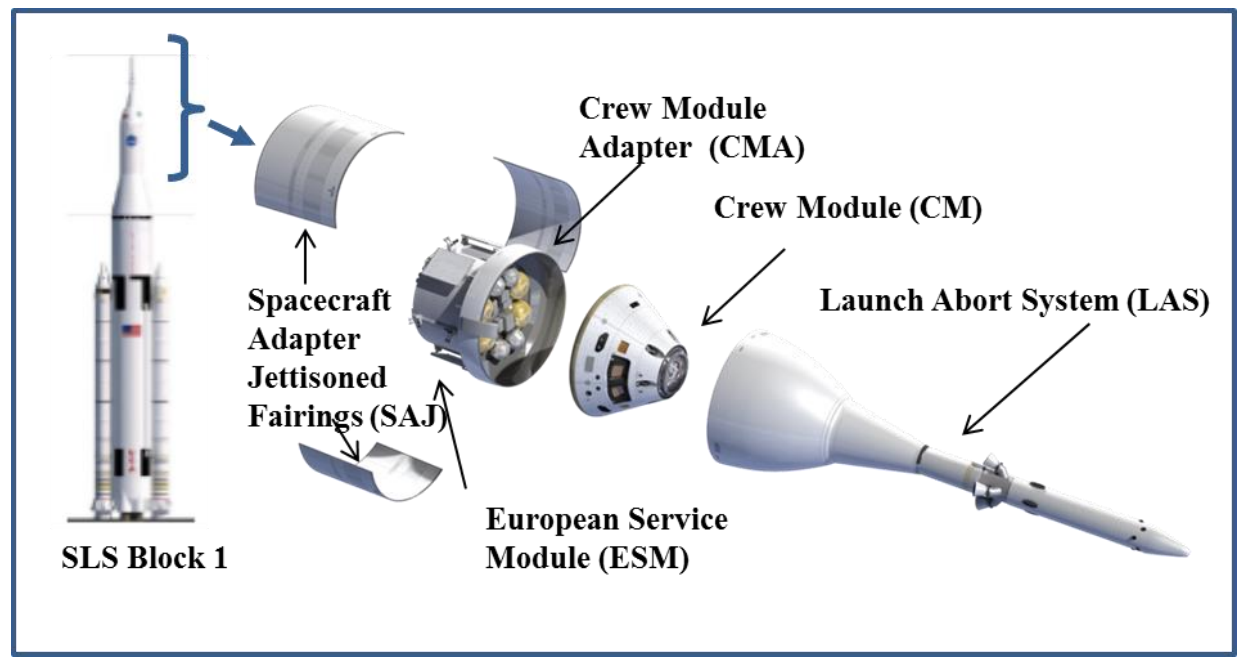

Figure 2. Orion spacecraft configuration is comprised of a LAS, CM, CMA/ESM, and SAJ elements.

The EM-1 CM contains the majority of TPS systems for on-orbit and re-entry mission phases. The re-entry environments are similar for Apollo and Orion for a lunar return where the initial re-entry velocity is approximately 7 miles per sec. A comparison of the Apollo and Orion capsules is shown in Figure 3 where the Orion capsule shape is very similar to the Apollo capsule, but scaled up in size. The Orion CM diameter is $22 \%$ larger which results in a $50 \%$ increase in habitat volume. The Apollo mission requirements supported a crew of 3 for orbit mission duration of approximately 10 days. The Orion mission requirements support a crew of 4 for a 21 day or longer lunar mission. The size of the Orion CM has driven the heat shield to be one of the largest re-entry configurations for a lunar return. The Orion heat shield utilizes the Apollo proven ablator material, but in a block form bonded to a composite skin supported by a titanium skeleton structure. The back shells utilize Space Shuttle proven ceramic coated AETB8 tiles bonded to composite panels. The forward bay cover on the front of the CM is a metallic one piece part with bonded AETB-8 and Flexible Reusable Surface Insulation (FRSI). The heat shield, back shells, and the forward bay cover are assembled off line in the O\&C high bay and installed late in the vehicle assembly flow during CM closeout operations. The heat shield and back shells are removed after CM return to enable future refurbishment operations for subsequent missions. Although the forward bay cover is not recovered, the heat shield and back shells are replaced after each flight with new TPS. 


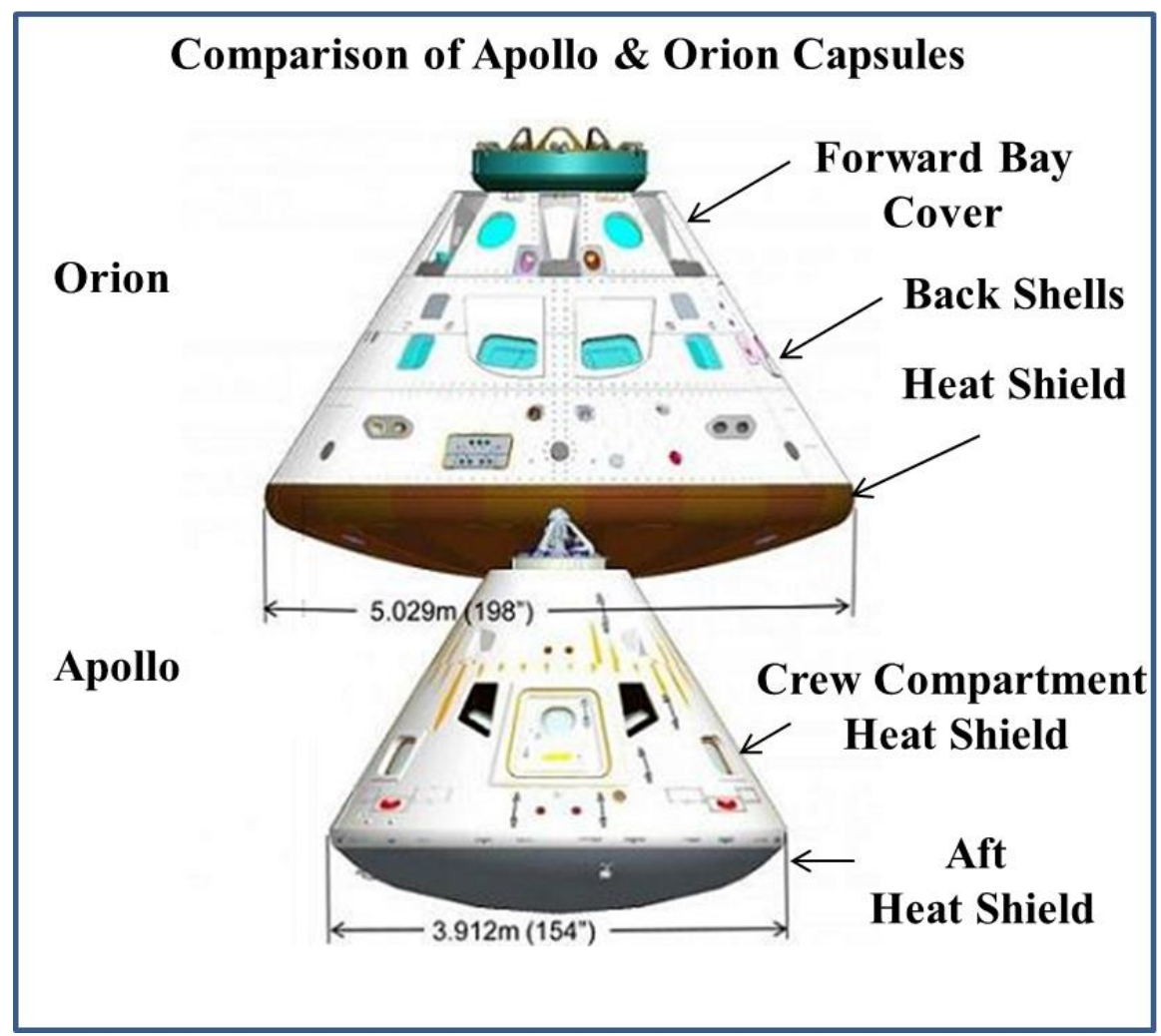

Figure 3. Comparison of Orion and Apollo CM identifying the forward bay cover, back shells, and heat shield on Orion.

The Neil Armstrong Operations and Checkout Facility (O\&C) at the Kennedy Space Center (KSC) as shown in Figure 4 is where the Orion manufacturing and test operations are performed to assemble the spacecraft to support NASA's exploration missions. The O\&C facility was originally established for the Apollo program in the 1960's to support the integration and checkout of the various spacecraft integrated on the Saturn V launch vehicle. In 2006 NASA began the Orion program and selected the O\&C facility as the location for spacecraft assembly, integration, and test. The O\&C was selected because as an existing facility it provided a lower cost and more affordable approach versus having to build a new facility. Additionally, its location at KSC eliminated the transportation and checkout costs that would be required if the spacecraft were manufactured at other locations across the country.

In order to affordably support the Orion program's manufacturing and test operational needs, the floor layout in the $\mathrm{O} \& \mathrm{C}$ was established with flexibility to accommodate spacecraft assembly and test operations evolution. Ten standard build positions were established with common utility drop outs in the floor and the supporting assembly tooling was standardized with free-standing capabilities to enable rapid repositioning as the vehicle assembly flows were adjusted. This approach enabled considerable offline processing to occur in parallel with the spacecraft assembly minimizing program cost and schedule. The TPS heat shield, back shells, and forward bay cover, assembly, inspection and test are accomplished in the O\&C high bay concurrent with the CM and SM vehicle assembly and test operations. Temporary build stations are located in the high bay to support offline TPS block and tile bonding to substrate structure, MLI blanket and thermal barrier fabrication and assembly operations. After these offline operations are completed, these positions are redeployed to support other subsystem operations in the high bay. The technicians that assemble the heat shield, back shells, and other TPS elements in the high bay are also supporting the final installations and closeouts of the TPS elements as well. This approach ensures timely integration of the heat shield, back shells, and forward bay cover into the spacecraft. In addition to the TPS assembly operations located in the O\&C, the existing Thermal Protection System Facility (TPSF) at KSC, which supported the Space Shuttle program, is utilized to provide the heat shield Avcoat blocks and the back shell and forward bay cover AETB-8 tiles for Orion program. This colocation of fabrication and assembly operations provides a seamless environment eliminating transportation cost and schedule benefits to support heat shield, back shell, and forward bay 
cover production rates in the future. A Thermal Cycle Chamber is located in the O\&C to provide heat shield assembly acceptance testing as well as the CM and SM systems acceptance testing operations.

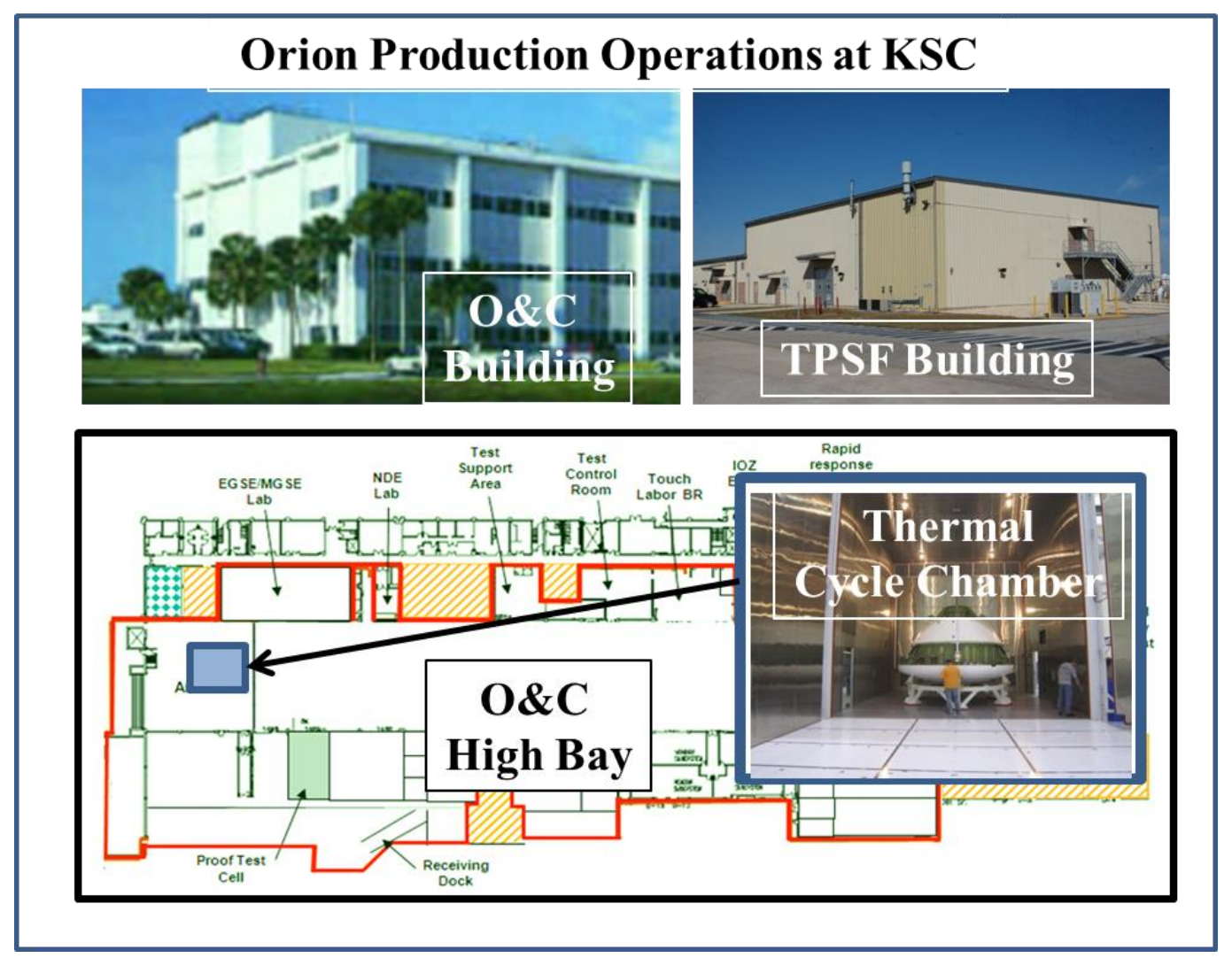

Figure 4. Orion production and test operations are located at the $O \& C$ building and TPS tile and ablative blocks are manufacturing at the TPSF at KSC.

\section{Apollo and Space Shuttle Thermal Protection Systems}

The Apollo and Space Shuttle programs were very successful in developing human rated spacecraft to travel to the moon and provide a sustainable earth to LEO transportation system. Both of these programs developed re-entry system designs that expanded the state of the art in TPS technology over several decades. Both programs developed and matured high temperature materials, manufacturing and inspection methods, and hardware verification approaches to provide reliable and safe TPS configurations to support the crewed space program missions. The Orion program is leaning heavily on the successes of the Apollo and Space Shuttle TPS experience to provide safe and reliable crew return capability for NASA's exploration missions. The Apollo program's capsule heat shield design and the Space Shuttle program's updated materials and bonding processes both contribute to the TPS approaches that benefit the Orion program.

The Apollo program was the third manned space program that developed TPS to safely return crew to earth with Mercury and Gemini programs retiring program risk along the way. The Apollo program was a very successful TPS program with no significant problems or anomalies associated with the TPS due to a conservative design philosophy combined with a rigorous analytical and test certification plans. As shown in Figure 5, the Apollo program developed and certified the Avcoat ablation material which was injected into stainless steel honeycomb panels for the heat shields on the CM. The Apollo program completed 11 crewed mission re-entry returns for both earth orbit and lunar missions. 


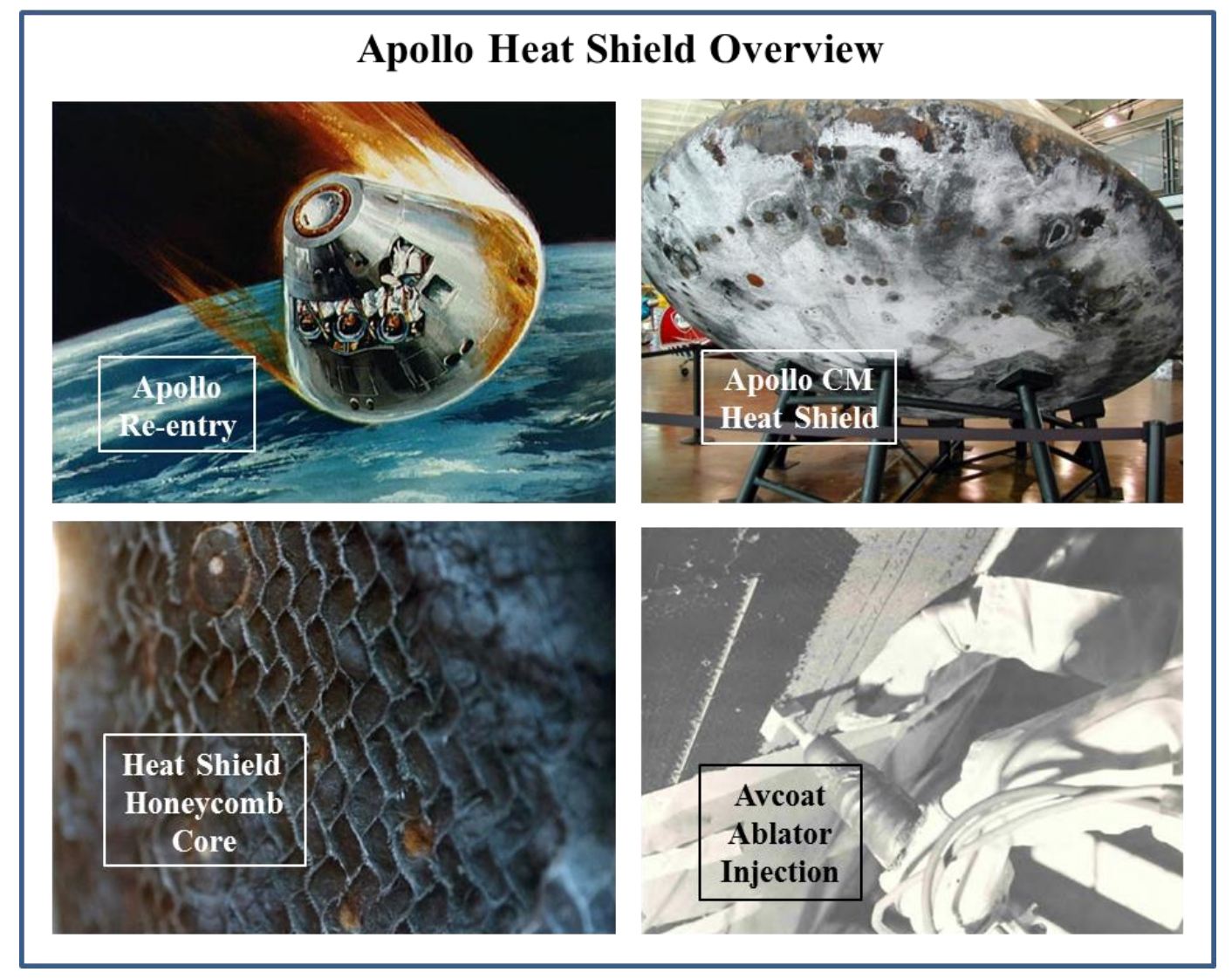

Figure 5. Apollo re-entry experience has provided the foundation for the Orion TPS heat shield design development program.

With the completion of the Apollo program, NASA began the development of the Space Shuttle to provide space access and return to support a variety of LEO missions including the International Space Station (ISS) program. The Space Shuttle program included new operational requirements that extended the TPS capabilities from Apollo which included reusability of the returned orbiter with turnaround requirements for a larger winged vehicle providing adequate cross range capability to return to earth for a variety of landing sites. As with the Apollo program, vehicle weight impact of the TPS designs were a challenging requirement throughout the Space Shuttle development and operational phases of the program. The TPS design solutions on the orbiter vehicle resulted in multiple TPS material and configuration designs to meet these challenging operational and light weight objectives for the Space Shuttle program as shown in Figure 6. Several TPS materials were utilized based on maximum operating thermal environments at specific locations on the orbiter including tiles, insulation blankets, and Reinforced Carbon-Carbon (RCC) panels. Although low cost operational requirements would have preferred a limited number of TPS designs, vehicle weight impact became a priority. Critical high temperature re-entry surfaces on the nose and leading edges of the fuselage wing sections required High Temperature Reusable Surface Insulation (HRSI) which included a other ceramic tile configurations including AETB-8 and RCC materials. Reusability requirements for the large acreage surfaces necessitated removable segments of tile and panel sections to allow access for maintenance and repair of vehicle systems to support turnaround timelines for re-flight of each orbiter. Tile bonding processes were developed to verify the TPS installations resulting in considerable experience in processing large numbers of tiles during the Space Shuttle program. This resulted in a very mature and robust TPS application capability that has benefited the Orion program. The Orion program baselined AETB-8 tiles directly from the Space Shuttle program for use on the back shells and forward bay cover on the $\mathrm{CM}$ and utilized proven bonding processes for the Avcoat in block configurations for the CM heat shield. 


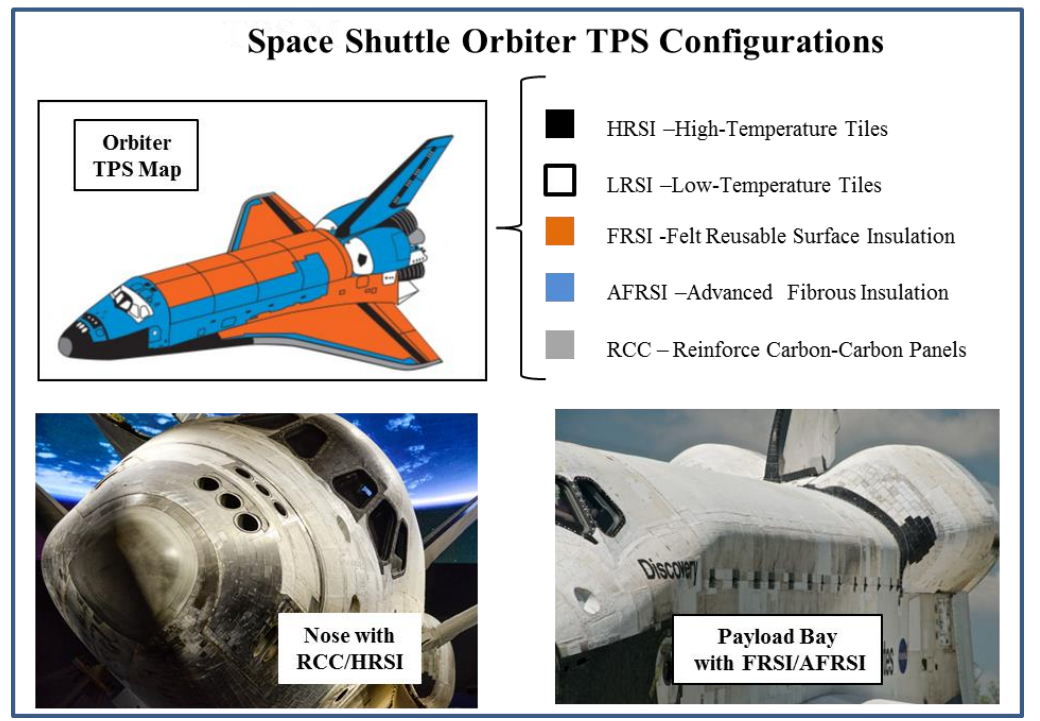

Figure 6. Space Shuttle program continued the NASA TPS heritage of advanced materials, manufacturing and installation processes benefiting the Orion program.

In addition to the Space Shuttle experience on TPS acreage insulation materials, the orbiter penetrations, closeouts, and access doors and panels utilized thermal barriers to prevent the high temperature gases from entering the interior compartments. Thermal barrier materials and installation concepts were developed and matured on the Space Shuttle program for a variety of applications and have been utilized on the Orion program for the hatches and other TPS interfaces. The orbiter interior compartments required additional temperature controls and required thermal blanket insulation for critical areas where Multi-Layer Insulation blanket systems were developed. Typical Thermal barrier and MLI materials are shown in Figure 7 and have been utilized on the Orion CM as part of the TPS configurations.

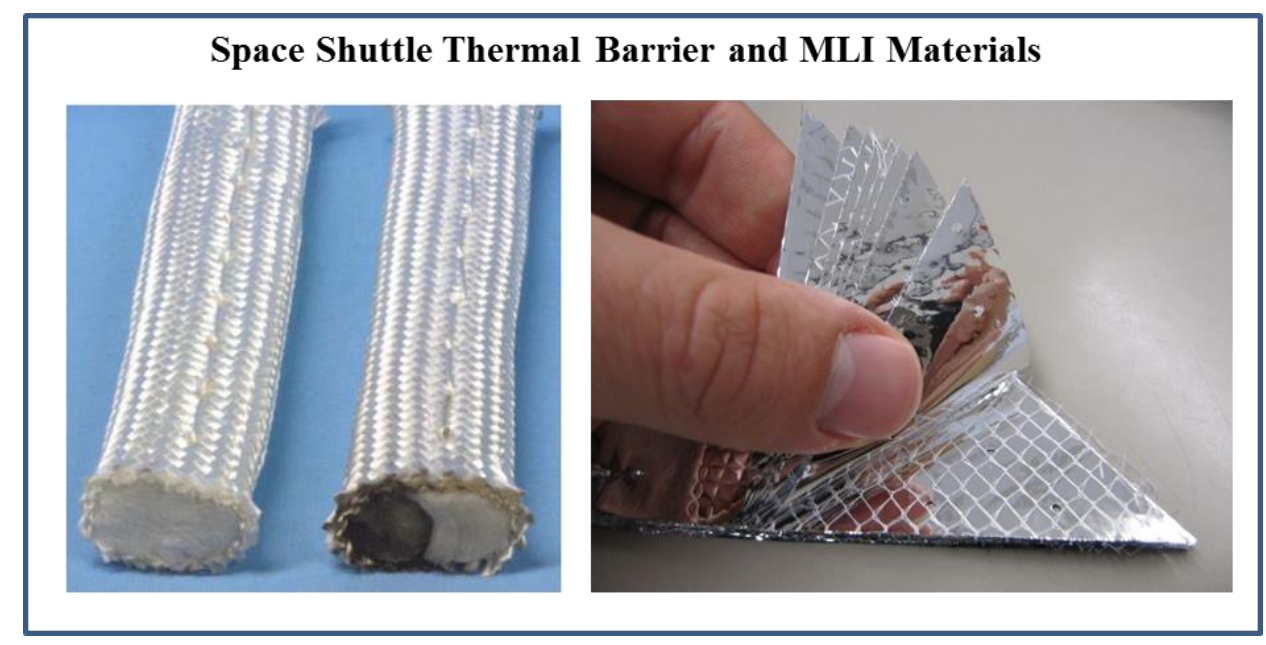

Figure 7. Space Shuttle TPS thermal barriers and Multi-Layer Insulation (MLI) systems are used on the Orion program. 


\section{EFT-1 Flight Test}

The Orion program successfully completed the EFT-1 flight test in 2014 which performed the launch, on-orbit maneuvers and re-entry phases of the mission as shown in Figure 8. This flight test vehicle was the first vehicle to be manufactured and tested in the Neil Armstrong Operations and Checkout facility at KSC and was an early risk reduction demonstration for the functionality of the TPS for capsule safe return to earth. The approach for the EFT1 heat shield utilized a proven approach using Apollo heritage design and manufacturing processes using an Avcoat TPS ablator with a honeycomb substrate to provide a one piece heat shield to meet the mission re-entry heating environments. The manufacturing processes used honeycomb cell injection guns which were redeveloped from the Apollo processes to build the EFT-1 heat shield. The back shells and forward bay cover utilized the Space Shuttle high temperature AETB-8 tiles and proven bonding and inspection processes. The completed heat shield was transported across the country by aircraft to the $\mathrm{O} \& \mathrm{C}$ for installation onto the capsule. The back shells and forward bay cover were assembled in the O\&C high bay in offline areas and directly integrated into the capsule. The EFT-1 capsule performed as required during its mission and successfully experienced $\sim 80 \%$ of the re-entry velocity for a lunar return for an exploration mission. A significant benefit of the returned CM was the ability to conduct post flight assessment of the hardware to support producibility improvements.

Post flight analysis of EFT-1 determined that all of the critical test objectives were met including the performance of the heat shield, back shells, and forward bay cover. The heat shield performed within expectations and was removed from the returned CM capsule for further evaluation. Post flight assessment of the EFT-1 heat shield was performed by NASA and results were provided to the EM-1 heat shield team to support design changes to meet the increased thermal requirements for the lunar return missions and for producibility improvements to reduce cost and schedule impacts to the program. The EFT-1 flight test objectives for the TPS contained three goals including TPS thermal-structural performance during re-entry environments, TPS thermal-structural performance during the launch and on-orbit environments, and structural performance during splash down loads. The heat shield and back shells were in good shape overall after the mission and responded as expected for nominal re-entry and landing conditions. Producibility trades were conducted on the fabrication and installation processes of the Apollo heritage heat shield approach indicating significant benefits of program schedule and cost reduction opportunities. The program determined the EM-1 heat shield design would be updated using an Avcoat Block configuration bonded to a carbon skin / titanium skeleton structure with the assembly moved to the O\&C. The back shells and forward bay cover TPS tiles performed well for the EFT-1 mission and were further optimized based on the EFT-1 flight test results for the EM-1 and exploration missions. The tile shapes or plan forms were updated to improve producibility, provide better alignment with heating flow characteristics and CM penetrations. Tile thicknesses were also tailored to meet the lunar re-entry environments. 


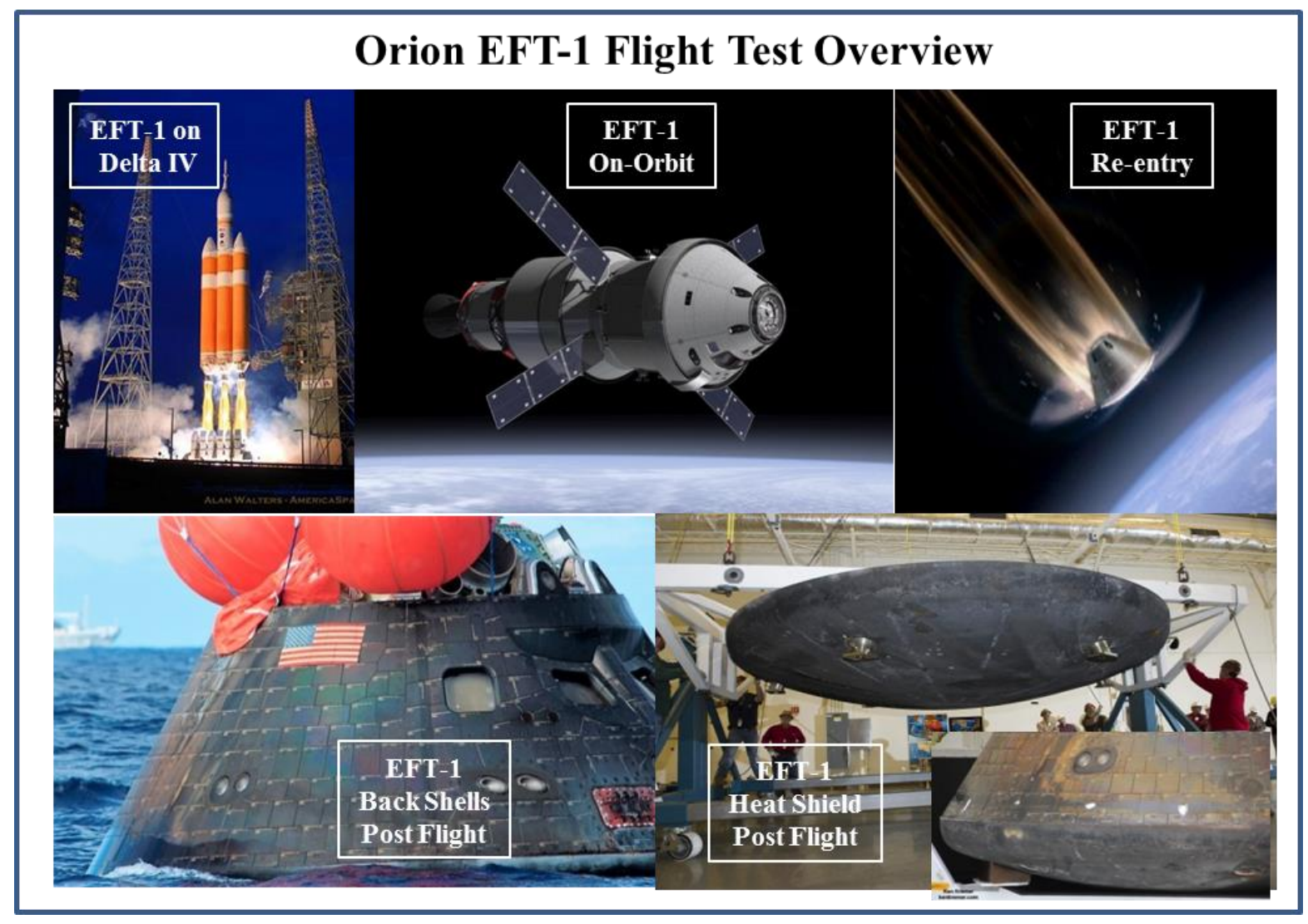

Figure 8. Orion's EFT-1 first flight test demonstrated TPS proof of concept approach and provided post flight data to support improvements in design and processes for the EM-1 heat shield and back shells.

The trajectory for the EFT-1 mission included a two orbit mission which was designed to demonstrate the reentry capability of the TPS systems for a lunar re-entry. The mission lasted for 4 hours and achieved a maximum apogee altitude of 3600 miles. The EFT-1 spacecraft flew through a high flux density Micrometeoroid (MM) zone at approximately 1800 miles and a high Orbit Debris (OD) zone at approximately 450 miles. While the CM heat shield is protected from MMOD environments by the CMA structure, the back shells are exposed to the MMOD environments during the near earth orbit altitudes. Inspection of the EFT-1 CM after the mission yielded six impact Regions of Interest (ROI) on the back shells and Figure 9 indicates one of the impacts. Three of these impacts were due to MM and three additional impacts were due to OD. Although these impacts did not effect the back shell TPS performance, the MMOD impacts will be used for further evaluation for future missions. 


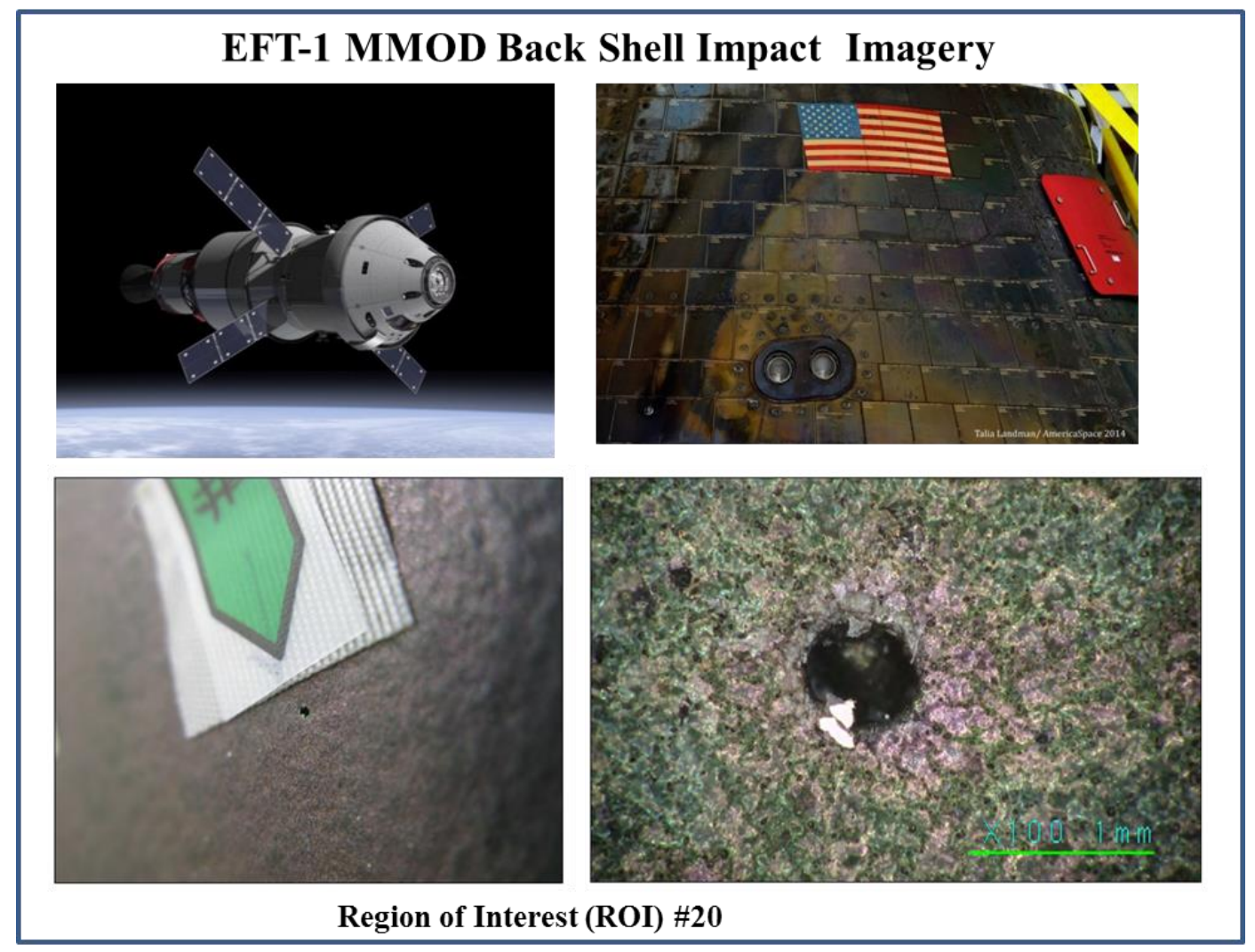

Figure 9. The EFT-1 flight experience provided insight into the MMOD environments to the exposed back shell TPS tiles. Six impacts were recorded and are in evaluation (typical is shown above).

TPS designs for earth re-entry spacecraft are dependent on a variety of re-entry parameters including the reentry trajectory velocity. Table 1 indicates the overall re-entry velocity comparison for a typical Space Station LEO mission, the Orion EFT-1 flight test, and an Orion Lunar return for the EM-1 flight test. The Lunar return entry velocity that the Orion EM-1 is designed for is 7 miles/second. The EFT-1 flight test was able to achieve an entry velocity of $80 \%$ of the EM-1 design requirements at 5.6 miles/second. Typical re-entry velocities for LEO missions such as for the ISS are at 4.7 miles/second. The heat load impacts for TPS designs are dependent on several parameters including the vehicle shape, trajectory profile and entry velocities. The heat load increase for the Orion EM-1 Flight Test is expected to be approximately 50\% greater than the EFT-1 Test program.

\begin{tabular}{|l|c|c|c|}
\hline Comparison of Spacecraft Earth Re-Entry Velocities by Trajectory \\
\hline Mission & ISS Return & $\begin{array}{c}\text { Orion Flight } \\
\text { Test EFT-1 }\end{array}$ & $\begin{array}{c}\text { Orion Flight } \\
\text { Test EM-1 }\end{array}$ \\
\hline Orbit & LEO & Elliptical & Lunar Return \\
Re Entry Velocity (Miles/sec) & 4.7 & 5.6 & 7 \\
\hline
\end{tabular}

Table 1. Orion flight test missions experience higher re-entry velocities relative to LEO missions.

\section{EM-1 Flight Test}

The Orion CM TPS configuration is derived from the Apollo and Space Shuttle programs utilizing proven materials and assembly processes. The Orion heat shield configuration as shown in Figure 10 utilizes the Avcoat 
ablative material from Apollo which was injected into a honeycomb substrate and has been updated incorporating a block configuration bonded to a composite shell structure. This approach utilizes the proven Avcoat material for the heat shield ablator and utilized advanced bonding verification processes and techniques derived from the Space Shuttle tile experience. The heat shield support structure was redesigned for producibility improvements resulting in a reduced part count and structural weight reduction. A significant change to the heat shield manufacturing approach for EM-1 was established locating the heat shield block bonding at the O\&C adjacent to the block machining at the TPSF at KSC. The composite and titanium support structure is delivered to the O\&C without the TPS installed eliminating the transportation risk of a completed heat shield, and provides the opportunity to pre-fit the structure to the CM before TPS bonding operations are performed.

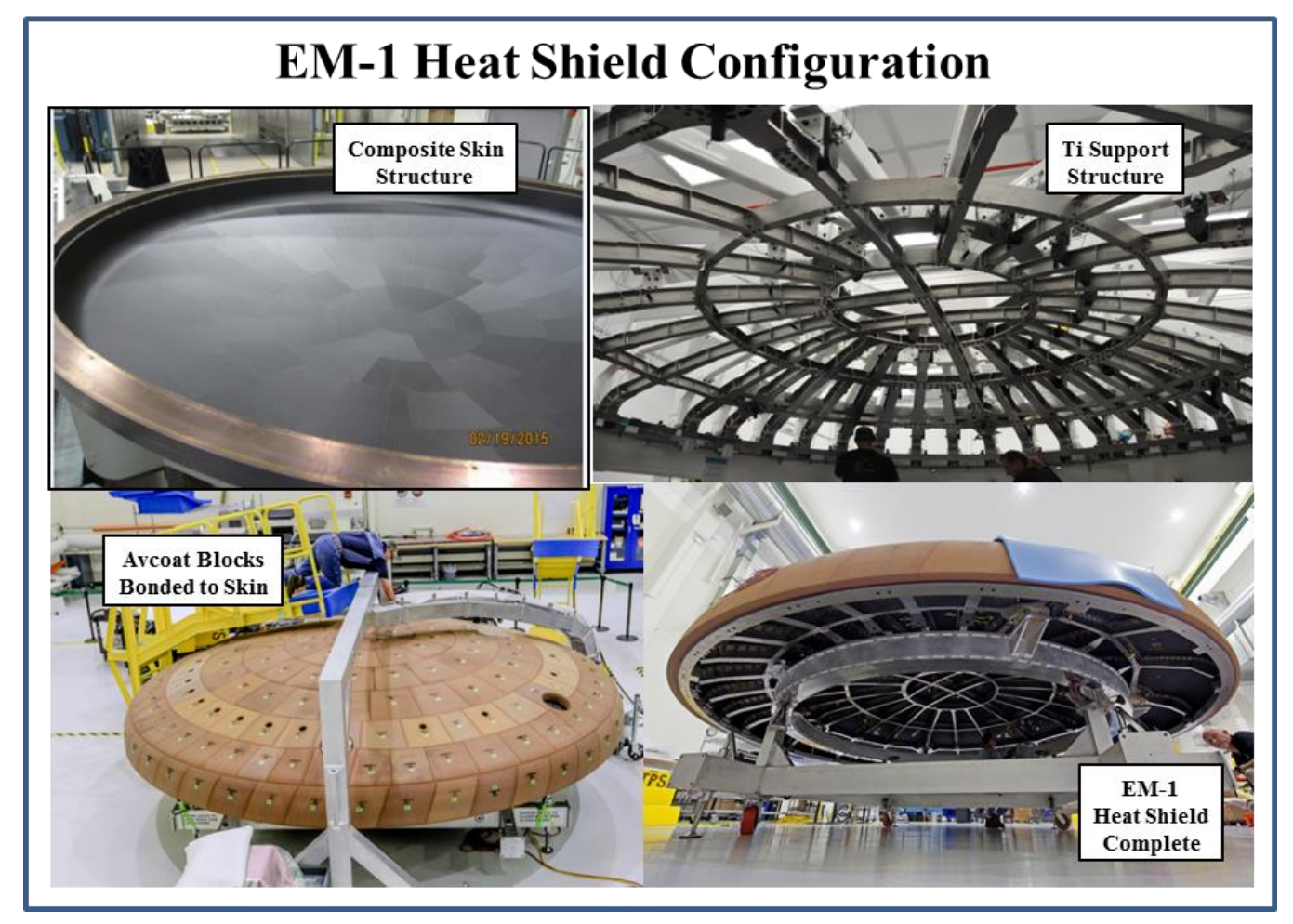

Figure 10. Orion EM-1 heat shield incorporated EFT-1 flight experience and incorporated producibility design improvements reducing program cost and schedule impacts.

The Orion back shell TPS configuration as shown in Figure 11 is based on Space Shuttle tile designs using proven tile materials and processes. The back shell tiles are derived from the Space Shuttle tile designs and are bonded to the CM composite substrate panels and use similar bonding and inspection techniques derived from Space Shuttle proven processes. Orion back shell tiles are fabricated utilizing the TPSF and the assembly and installation operations are performed at the O\&C high bay at KSC. This approach provides a seamless co-located TPS tile operation to enable an affordable manufacturing, installation, inspection, repair and replacement of tiles during TPS processing on the Orion program. The tiles are fabricated at the TPSF facility using Space Shuttle proven process and delivered to the $\mathrm{O \& C}$ high Bay to be fitted and installed on the back shell panels in offline positions in the high bay adjacent to the Orion spacecraft assembly operations. This approach improves back shell tile bonding and panel pre-fit up operations concurrent to the spacecraft assembly operations. Damage to back shell panel tiles can be easily addressed in the O\&C high bay. Another benefit to the seamless back shell operations is the synergy of TPS technician skills utilization for tile bonding and back shell installation into the spacecraft. 


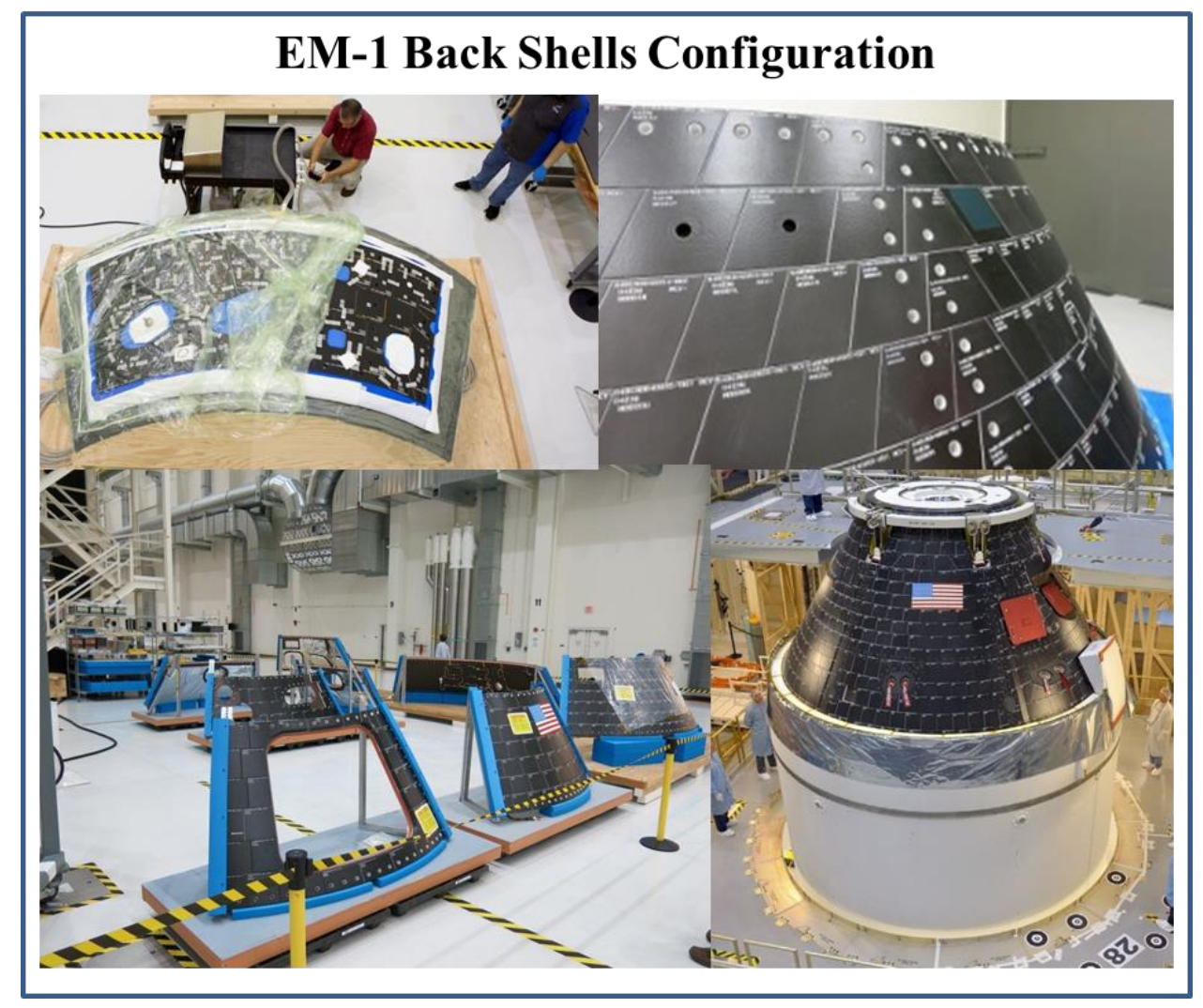

Figure 11. Orion back shell panels utilize Space Shuttle AETB-8 tiles and are assembled and installed in a seamless operation in the $O \& C$ high bay reducing program cost and schedule.

The Space Shuttle program developed, matured and improved TPS tile operations over several decades of operations on five orbiters and many thousands of tile bonding operations. A product of this experience is establishing proven bonding verification processes and plans providing safe and reliable TPS hardware for human rated spacecraft. The Orion program benefits from the maturity of these processes and controls developed on the Space Shuttle program by using these verification methods for the heat shield blocks, inspection, and test methods and tile pull test methods as shown in Figure 12. The Orion TPS block verification process consists of three elements to ensure the TPS meets all of the design and manufacturing requirements including process controls, Non Destructive Evaluation (NDE), and acceptance testing. The process controls ensure that the bonding operations are performed within specification and process requirements for operations including surface preparations, block mismatch alignment, and adhesive mixing operations. Process operations are monitored and recorded to provide objective evidence of process compliance to all bonding operations. Bonding specimen samples are fabricated concurrently to flight hardware bonding to perform offline test and inspections to verify the processes are meeting the adhesive requirements. Visual and NDE inspection processes leveraged from the Space Shuttle program including Ultrasonic and X-ray inspections are utilized to identify any unacceptable bonding defects such as "kissing" bonds and lack of adhesion or missing bonds are present in the hardware. Acceptance criteria for bond quality are based on Space Shuttle process experience where Probability of Detection (POD) criteria for NDE techniques have been certified for the block bonding configurations. After the heat shield assembly in completed, NDE inspections are performed and specimen samples testing are completed. The heat shield is subjected to a thermal acceptance test in the Thermal Cycle Chamber in the O\&C and post-test NDE inspections are conducted to complete the verification acceptance plan. Any anomalies resulting in rework in this assembly process can be easily accommodated in the O\&C high bay with minimum program impact. 


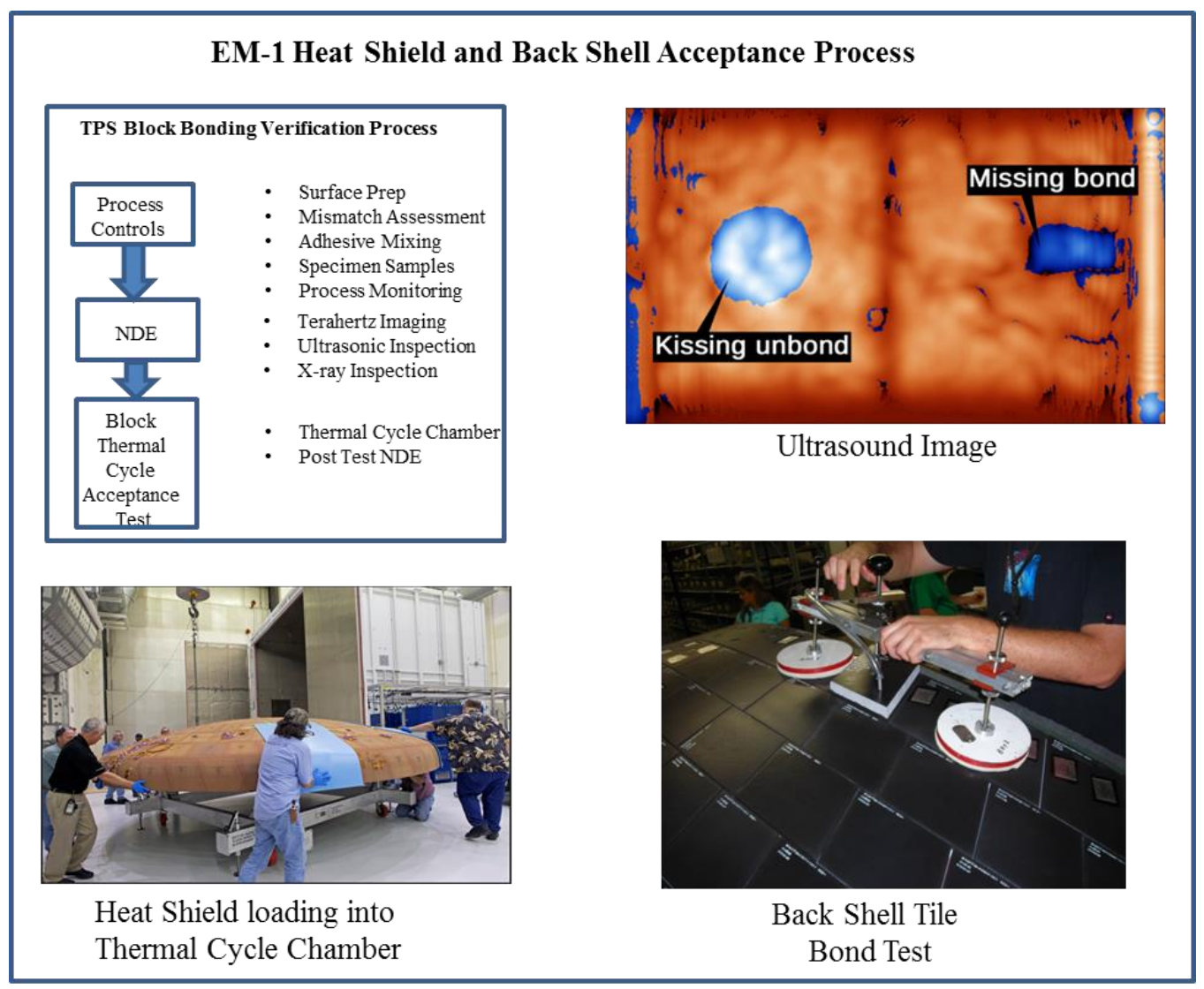

Figure 12. Orion utilizes Space Shuttle proven verification processes to achieve human rated TPS hardware for heat shield and back shell panels.

A significant benefit to the Orion program is the transitioning of the Space Shuttle technician work force at KSC. This highly skilled workforce was easily able to transition to the Orion program and immediately support the TPS installation operations as shown in Figure 13. They brought with them the human rated manufacturing and assembly operations culture that was critical to the Space Shuttle success avoiding the retraining cost and schedule impacts of a new workforce to Orion. The technician skills certification program from the Space Shuttle was found to be compatible with the Lockheed Martin (LM) technician certification programs enabling a seamless training process utilizing process similarity avoiding the cost of retraining the entire Space Shuttle work force to Orion standards. The existing workforce is certificated for multiple TPS processes enabling timely reassignment of technicians to other tasks in the Orion TPS operations reducing the overall touch labor manpower requirements. Additional benefits of using the Space Shuttle workforce is the incorporation of the lessons learned from Space Shuttle processes to improve the Orion TPS processes. This has resulted in a continuous evolution of TPS processes to improve the producibility and reduce the programmatic risk for the TPS hardware for future Orion spacecraft. 


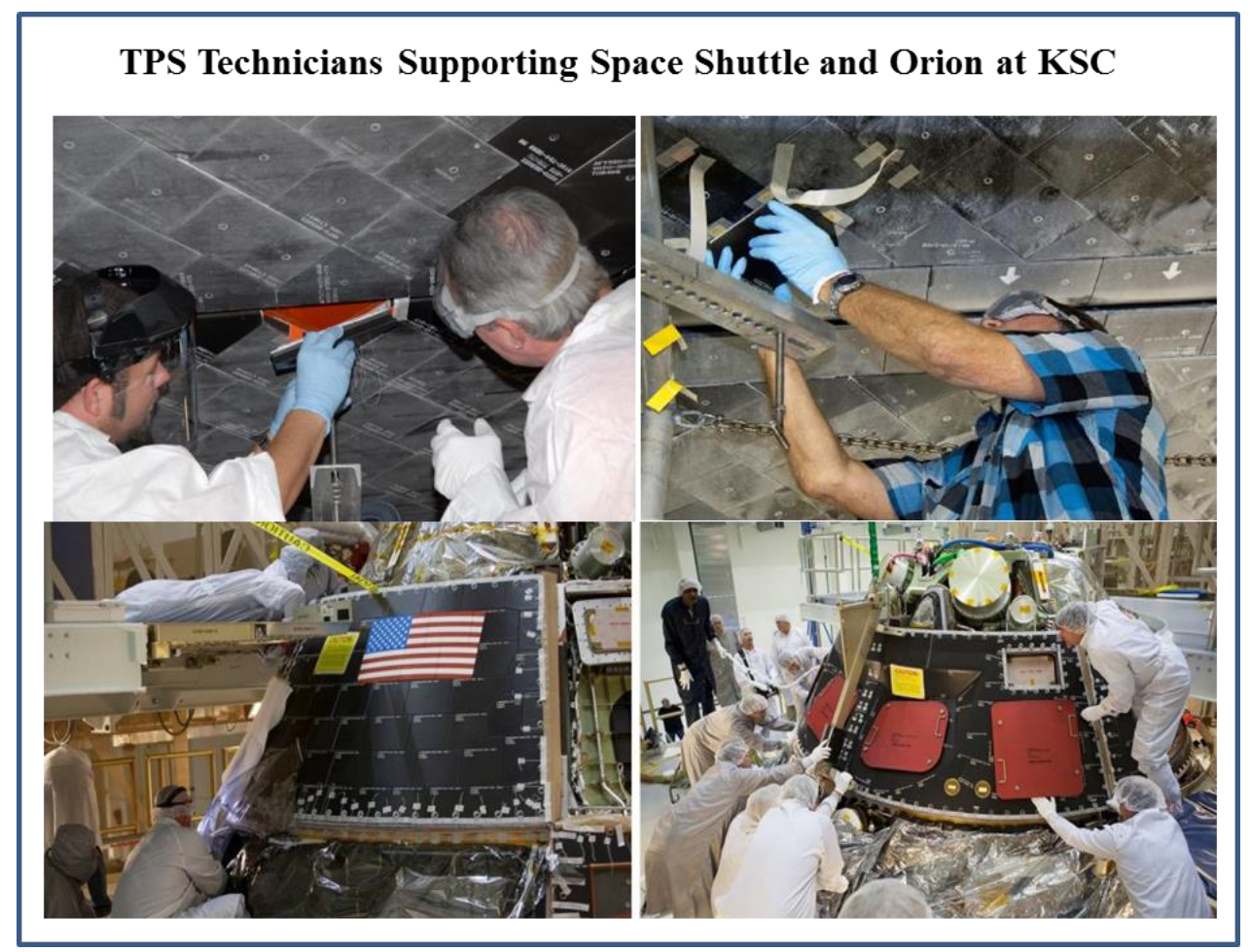

Figure 13. Orion TPS production operations transitioned the existing Space Shuttle skilled technicians at KSC to support the Orion program.

Transitioning NASA's Apollo and Space Shuttle TPS experience in design approaches, processes, and technician workforce has been instrumental in enabling Orion to successfully meet the program challenges with minimal cost and schedule impacts as shown in Table 2. This table identifies the TPS experience from Apollo and Space Shuttle programs, the transfer of specific technologies to the Orion Program and maps the specific benefits of program cost and schedule reductions. This approach has enabled Orion to successfully complete an early EFT-1 flight test in 2014 and to develop affordable manufacturing and assembly TPS designs and processes for EM-1 and subsequent exploration missions. 


\begin{tabular}{|c|c|c|c|c|c|}
\hline \multicolumn{6}{|c|}{ TPS Technology Transfer from Apollo and Space Shuttle to Orion } \\
\hline \multirow{2}{*}{$\begin{array}{l}\text { NASA } \\
\text { Program }\end{array}$} & $\begin{array}{l}\text { TPS Rqmts, Design \& } \\
\text { Manufacturing }\end{array}$ & TPS Experience \& Technology & Orion TPS Design \& Processes & \multicolumn{2}{|c|}{ Orion Benefits } \\
\hline & & & & Cost & Schedule \\
\hline \multirow[t]{4}{*}{ Apollo } & Capsule Shape & Similar Aspect Ratio & Heritage Design and Interfaces & $\mathrm{X}$ & $\mathrm{X}$ \\
\hline & $\begin{array}{l}\text { Lunar Mission } \\
\text { Environments }\end{array}$ & $\begin{array}{l}\text { Re-entry velocity } \sim 7 \text { Miles/sec, } \\
\text { MM }\end{array}$ & Well understood Environments & $\mathrm{X}$ & $\mathrm{X}$ \\
\hline & $\begin{array}{l}\text { TPS Materials (Heat } \\
\text { Shield) }\end{array}$ & Avcoat/Honeycomb Substrate & Heat Shield Ablator Experience & $\mathrm{X}$ & $\mathrm{X}$ \\
\hline & Heat Shield Processes & Avcoat Injection & Machined Avcoat Blocks & $\mathrm{X}$ & $\mathrm{X}$ \\
\hline \multirow[t]{24}{*}{ Shuttle } & TPS Materials & Heat Shield Configuration & Bonded Avcoat Blocks & & \\
\hline & & Heat Shield Gaps & RTV 560-5PMB & $\mathrm{X}$ & $\mathrm{X}$ \\
\hline & & Backshell Tile & AETB-8 & $\mathrm{X}$ & $\mathrm{X}$ \\
\hline & & Backshell Closeouts & Carbon Phenolic & $\mathrm{X}$ & $\mathrm{X}$ \\
\hline & & Docking Hatch & FRSI & $\mathrm{X}$ & $\mathrm{X}$ \\
\hline & & Forward Bay Cover & AETB-8 & $\mathrm{X}$ & $X$ \\
\hline & & Thermal Barriers & Barriers with Inconel Springs & & \\
\hline & & Multi-Layer Insulation & Radiation Blankets / Coated Foil & & \\
\hline & & Thermal Radiation Coating & Silver Tape Installation & $\mathrm{X}$ & $\mathrm{X}$ \\
\hline & TPS Processes & Adhesive Bonding & Avcoat Blocks / AETB-8 Tiles & & \\
\hline & & Manuf. of Blocks/Tiles & Fab of Billets and Machining & $\mathrm{X}$ & \\
\hline & & Visual Inspection & Proven Acceptance Criteria & $\mathrm{X}$ & \\
\hline & & NDE Methods & Phased Array, UT, X-ray, Pull Tests & $\mathrm{X}$ & \\
\hline & & Process Controls & $\begin{array}{l}\text { Specimen Samples, Contamination } \\
\text { Controls, Existing Databases }\end{array}$ & & \\
\hline & & Cleanliness Operations & $\begin{array}{l}\text { Selected Control levels based on TPS } \\
\text { requirements }\end{array}$ & & \\
\hline & & Tile Repair Processes & AETB- 8 & $\mathrm{X}$ & $\mathrm{X}$ \\
\hline & & TPS Verification Plans & Heritage Risk Mitigation Methods & $\mathrm{X}$ & \\
\hline & Technicians & Existing Workforce @ KSC & TPS Skills \& Experience & $\mathrm{X}$ & \\
\hline & & Training \& Certification & Heritage LM \& USA Plans & $\mathrm{X}$ & \\
\hline & & Workforce Sustainability & Next Gen Intern/Mentoring & $\mathrm{X}$ & \\
\hline & & HSF Culture & Heritage Experience & & \\
\hline & Facilities \& Equip & TPSF & Tile/Block Manuf. \& Machining & $\mathrm{X}$ & \\
\hline & & & Adjacent to Orion AI\&P Ops & & $\mathrm{X}$ \\
\hline & & O\&C High Bay & $\begin{array}{l}\text { All TPS AI\&P Perfomed in O\&C using } \\
\text { Flexible Foor Space Allocation }\end{array}$ & $\mathrm{X}$ & $\mathrm{X}$ \\
\hline
\end{tabular}

Table 2. The TPS technology transfer from Apollo and Space Shuttle programs has benefited the Orion program with program risk reduction resulting in cost and schedule benefits.

The Orion program extended the TPS experience from Apollo and Space Shuttle programs by establishing an affordable and robust Assembly, Integration and Production (AI\&P) operations at KSC co-locating TPS materials fabrication and installation with the spacecraft assembly as shown in Table 3. Orion TPS producibility improvements have been enhanced by performing the heat shield and back shell manufacturing operations adjacent to the spacecraft assembly enabling seamless integration of TPS elements to the spacecraft. This is further enabled by establishing flexibility in floor space utilization, standardized processes across TPS systems, and transitioning a multi-skilled technician work force at KSC. This co-location approach is further enhanced by incorporating a thermal cycle test chamber in the O\&C facility to support acceptance testing of the heat shield and on site location of Avcoat block machining and tile fabrication at the TPSF at KSC. Updated spacecraft manufacturing 
documentation systems are also deployed across the TPS hardware using digital documentation processes and digital $\mathrm{X}$-ray operations. These technology enhancements provide cost and schedule benefits to the Orion TPS assembly and manufacturing operations.

\begin{tabular}{|l|c|c|c|}
\hline \multicolumn{4}{|c|}{ Orion TPS Manufacturing Enhancements Summary } \\
\hline $\begin{array}{l}\text { Orion TPS Assembly and Test } \\
\text { Operations }\end{array}$ & Orion TPS Enhancements & Orion Benefits \\
\hline & \multicolumn{1}{|c|}{ Cost } & Schedule \\
\hline $\begin{array}{l}\text { Co-location of Assembly, } \\
\text { Integration \& Test Operations }\end{array}$ & $\begin{array}{c}\text { Heat Shield Block Machining at TPSF, } \\
\text { Installation, Inspection, \& Test at O\&C } \\
\text { Thermal Cycle Chamber } \\
\text { Backshell Panel Tiles at TPSF, } \\
\text { Installation, Inspection at O\&C } \\
\text { Thermal Barriers, MLI fabricated and } \\
\text { installed at O\&C }\end{array}$ & $\mathrm{X}$ & $\mathrm{X}$ \\
\hline $\begin{array}{l}\text { Flexible Floor Space in the O\&C } \\
\text { w Clean Environment }\end{array}$ & $\begin{array}{c}\text { O\&C High Bay and Offline Areas } \\
\text { Support TPS Installation Ops }\end{array}$ & $\mathrm{X}$ & $\mathrm{X}$ \\
\hline $\begin{array}{l}\text { Flexible Technicain Work Force } \\
\text { w Proven Heritage }\end{array}$ & $\begin{array}{c}\text { Cross Trained Skills, Equivalence } \\
\text { Technician Certifications, HSF Culture }\end{array}$ & $\mathrm{X}$ & $\mathrm{X}$ \\
\hline Enhanced \& Proven Processes & $\begin{array}{c}\text { Digital Engineering/Manufacturing } \\
\text { Environment }\end{array}$ & $\mathrm{X}$ & $\mathrm{X}$ \\
\hline $\begin{array}{c}\text { Proven NDE Processes: Digital } \\
\text { Xray,Phased Array, UT Methods } \\
\text { TPS Proven Process Control Plans }\end{array}$ & $\mathrm{X}$ & $\mathrm{X}$ \\
\hline
\end{tabular}

Table 3. Orion program has extended NASA's TPS experience with manufacturing enhancements at KSC to further reduce cost and schedule impacts.

\section{Conclusion}

The Orion program has made considerable progress in developing a crew transportation capability to meet NASA's future manned exploration missions. NASA has recently established a near term lunar mission concept called Lunar Orbital Platform - Gateway as shown in Figure 14. This mission is the next step in the exploration missions to mars which is comprised of a crewed lunar station demonstrating mission operations in deep space while in near proximity to the earth enabling a low cost program with a low risk lunar return of crew to earth. Orion is a critical element in this mission providing crew transportation to and from the lunar orbit station. Cost projections for manned exploration missions are considerable and their affordability is enhanced if Orion costs can be kept to a minimum. The Orion program is utilizing the TPS experience from the Apollo and Space Shuttle programs providing an affordable approach to meet NASA's exploration missions in the near future. 


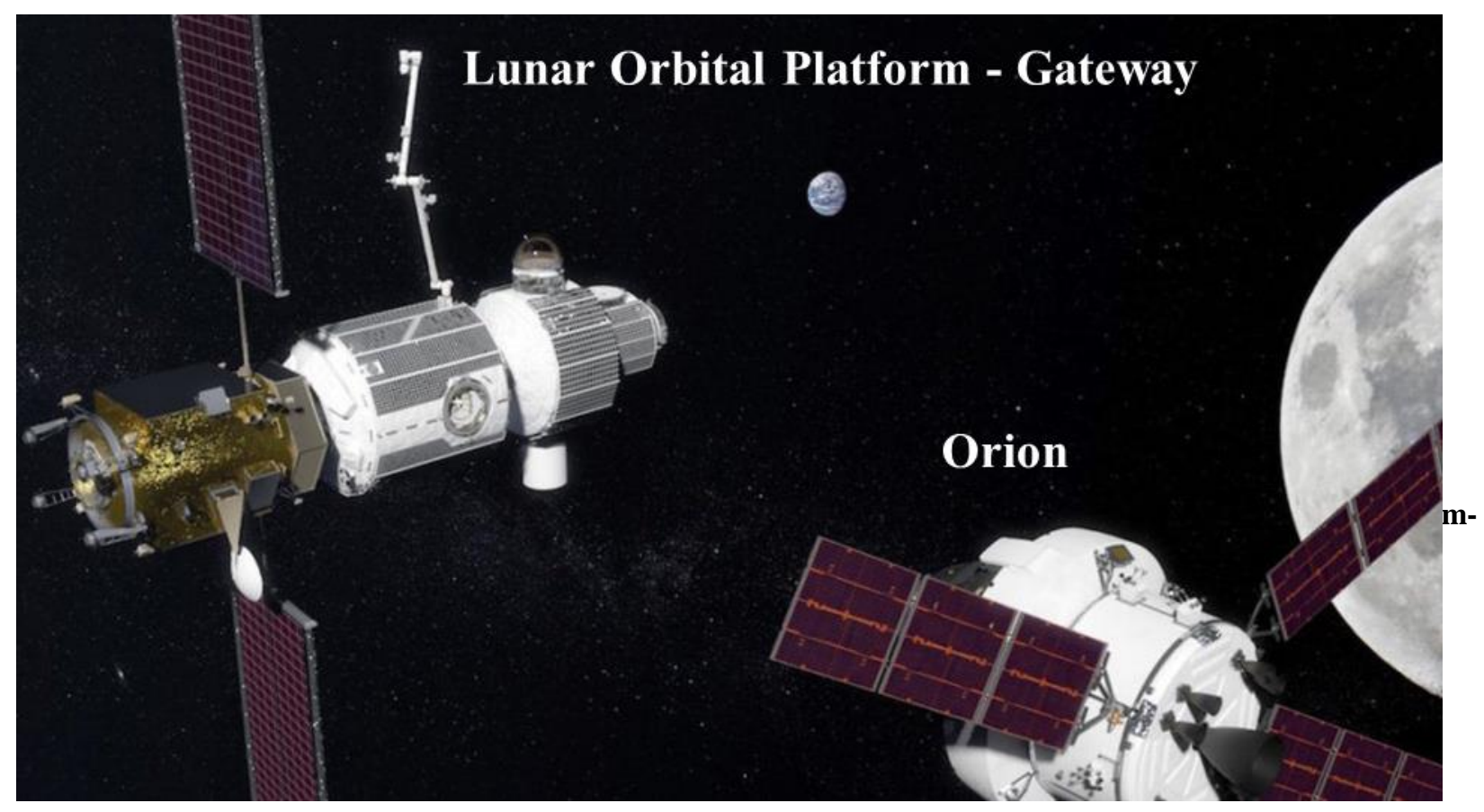

